\title{
Detection and Estimation of Damage Caused By Thrips Thrips tabaci (Lind) of Cotton Using Hyperspectral Radiometer
}

Ranjitha G*, MR Srinivasan and Abburi Rajesh

Tamil Nadu Agricultural University, Coimbatore, Tamil Nadu, India.

"Corresponding author: Ranjitha G, Tamil Nadu Agricultural University, Coimbatore, Tamil Nadu, India, Tel: +917207342580; E-mail: ranjithagurram@gmail.com Rec date: Mar 15, 2014, Acc date: May 15, 2014, Pub date: May 17, 2014

Copyright: ( 2014 Ranjitha G, et al. This is an open-access article distributed under the terms of the Creative Commons Attribution License, which permits unrestricted use, distribution, and reproduction in any medium, provided the original author and source are credited.

\begin{abstract}
Hyper spectral radiometry helps in assessing crop condition in ground based and satellite remote sensing. Use of remote sensing techniques for detection of crop stress due to pests and diseases is based on the assumption that stresses induced by them interfere with photosynthesis and physical structure of the plant, affect absorption of light energy and thus alter the reflectance spectrum of plants. Field experiments were conducted to detect and estimate damage caused by thrips in Surabi variety from 70 to 90 days after sowing using spectroradiometer, from which canopy reflectance was recorded and vegetation indices (VIs) were worked out. The reflectance was a decrease in near infrared $(770-860 \mathrm{~nm})$ while blue $(450-520 \mathrm{~nm})$, green $(520-590 \mathrm{~nm})$ and red $(620-680 \mathrm{~nm})$ reflectance increased compared to undamaged plants. Red band (at wavelengths 691 and $710 \mathrm{~nm}$ ) and Green Red vegetative index (GRVI) were found to be more sensitive to thrips damage. The sensitivity curve shows single peak in blue region (at about $496 \mathrm{~nm}$ ) which is characteristic of the thrips damage. There was a significant negative correlation between damage and VIs with significant $\mathrm{R}^{2}$ values of VIs indicating their capability to estimate damage. Linear regression equations were developed based on spectral indices and pest damage and a relationship between pest damage and VIs was established. Thus, it was found that detection and estimation of damage caused by cotton thrips can be done using hyper spectral radiometry.
\end{abstract}

Keywords: Hyper spectral; Reflectance; Vegetative indices

\section{Introduction}

Remote sensing can be useful in detecting crop damage over a large area in a short time period. It is necessary to conduct ground level study to establish the relationship between actual pest infestation and the data obtained through satellite remote sensing. Recording the ground truth with the help of multispectral or hyper spectral spectroradiometer allow detection, identification and estimation of various crop stresses through analysis of their spectral signatures in a non-destructive way [1].

Earlier, multispectral data was useful in identifying reflectance obtained from crop due to incidence of pests and diseases [2], weeds and mites $[3,4]$ but due to its limited spectral coverage, multispectral remote sensors may not be able to uniquely identify the damagecausing stressor.

The development of hyper spectral remote sensing has satisfied the demand in providing qualitative and quantitative details of vegetation spectrum and help in assessing and evaluating crop condition parameters [5,6]. It also increases our ability to accurately map the vegetation attributes [7]. The utility of hyper spectral data to diagnose pests and diseases of vegetables can improve detection speed and provide opportunity for non-destructive sampling [8].

The present study was undertaken with the following objectives: (i) To compile spectral library of thrips damage symptoms. (ii) To determine the spectral bands and vegetative indices sensitive to thrips. (iii) To establish a relationship between thrips damage with vegetative indices.

\section{Materials and Methods}

Field experiments were conducted for detecting and estimating damage caused by thrips in cotton using hyper spectral radiometer at Tamil Nadu Agricultural University, Coimbatore. The damage was studied in winter irrigated variety Surabi, with observations taken from 70 to 90 days after sowing at different intervals when incidence of pest was noticed. Trips population was counted and damage was estimated in two plots/treatments (damaged and undamaged). The plants which were marked as undamaged, protected from insect damage by periodical spray of suitable insecticides while in the damaged plots (affected leaves became thickened, blistered and bronzed), no plant protection measures in the plot marked damaged. However, all the plots were kept disease free by monitoring and spraying fungicide/ bactericide carefully whenever necessary.

\section{Spectral reflectance}

Percent spectral reflectance was recorded from 70 to 90 days after sowing using the field portable Spectroradiometer (model: GER 1500). The canopy spectral data was collected by pointing the instrument at a distance of $30 \mathrm{~cm}$ above the cotton canopy on clear sunny days between $10 \mathrm{AM}$ and $1 \mathrm{PM}$ IST. The instrument was optimized, calibrated initially using barium sulphate panel (reference) and for every five minutes onwards to adapt to the changing atmospheric conditions as mentioned by Luther and Carroll $[9,10]$.

The percent reflection is calculated using the following formulae.

Percent reflectance $=\frac{\text { Reflectance from target }(\text { plant canopy })}{\text { Reflectance from reference }(\text { barium sulphate panel })} \times 100$

The 512 values of percent spectral reflectance of approximately 1.5 $\mathrm{nm}$ bandwidth from 276.86 to $1093.5 \mathrm{~nm}$ were obtained. The spectral 
reflectance in blue $(450-520 \mathrm{~nm})$, green $(520-590 \mathrm{~nm})$, red (620-680 $\mathrm{nm})$ and NIR (770-860 $\mathrm{nm})$ regions of electromagnetic spectrum were recorded. The wavelength ranges used in our experiments for green, red and NIR were taken to match the bands in the LISS III, LISS IV (Linear Imaging Self Scanning Sensor) and AWiFS (Advanced Wide Field Sensor) of latest Indian remote sensing satellites namely Resource at 1 and 2 . The blue band was taken to match with LANDSAT 7 Enhanced Thematic Mapper Plus (ETM+) sensor spectral bands.

\section{Band sensitivity analysis}

Sensitivity, at a given wavelength or band was computed by using the following formula [11].

Band Sensitivity $=\left[\left(\mathrm{R}_{\mathrm{INF}}-\mathrm{R}_{\mathrm{CTRL}}\right) / \mathrm{RCTRL}\right] \times 100$

Where, $\mathrm{R}_{\mathrm{INF}}$ and $\mathrm{R}_{\mathrm{CTRL}}$ were canopy reflectance of infested and control plants respectively.

The variation in light intensity between observations caused shifting of sensitivity curve along y-axis. In order to correct this, a corrected sensitivity was worked out as below. The reflectance in the wavelength range $350-370 \mathrm{~nm}$ was found to have no affect due to pest damage, based on preliminary observations. Hence, the average of sensitivity values between $350-370 \mathrm{~nm}$ was taken as zero. This was taken as correction factor and was applied to sensitivity values at other wavelengths by adding or subtracting. The corrected sensitivity values have been reported as the sensitivity values.

\section{Correlation intensity analysis}

Pearson correlation coefficient $(r)$ between the thrips infestation and the reflectance at each $1.5 \mathrm{~nm}$ wavelength was calculated from the pooled data and correlation intensity curves were plotted to assess the relationship between them. The spectral bands with high absolute correlation coefficient values at different peaks along the spectral domain were considered as sensitive bands for relating reflectance spectra to thrips infestation while those with small absolute correlation coefficients are considered unrelated to the pest damage [12-15]. These correlation values were plotted as a graph against the wavelengths to get the linear correlation intensity analysis graph as suggested by Luedeling et al. [16]. Similar to the band sensitivity analysis, this study will help to locate wavelengths most sensitive to pest damage.

\section{Vegetative indices}

Vegetation Indices (VIs) are different combinations of surface reflectance at two or more wavelengths designed to highlight a particular property of vegetation. It includes differences, ratios or linear combinations of reflected light in visible and NIR wavebands $[17,18]$ (Figure 1).

Normalized Difference Vegetation Index (NDVI) is the normalized difference of reflectance in NIR and red bands (Table 1).

$\mathrm{NDVI}=\left(\mathrm{R}_{\mathrm{NIR}}-\mathrm{R}_{\mathrm{RED}}\right) /\left(\mathrm{R}_{\mathrm{NIR}}+\mathrm{R}_{\mathrm{RED}}\right)$

Ratio Vegetative Index (RVI) is the ratio of the reflectance in NIR and red bands $[19,20]$. They were used to detect plant stress and can be saturated at high leaf area index $(\mathrm{LAI})$. RVI $=\mathrm{R}_{\mathrm{NIR}} / \mathrm{R}_{\mathrm{RED}}$
Green Red Vegetation Index (GRVI) show small changes in vegetation condition during crop growth and calculated using the following formulas [21].

$$
\mathrm{GRVI}=\left(\mathrm{R}_{\mathrm{GREEN}}-\mathrm{R}_{\mathrm{RED}}\right) /\left(\mathrm{R}_{\mathrm{GREEN}}+\mathrm{R}_{\mathrm{RED}}\right)
$$

Where $R_{R E D}, R_{G R E E N}$ and $R_{N I R}$ were reflectance at red, green and NIR bands respectively.

\section{Sensitivity analysis of vegetative indices}

Sensitivity for given vegetation index was calculated by using the following formula,

\section{Vegetative Index Sensitivity $=\left[\left(\mathrm{VI}_{\mathrm{INF}}-\mathrm{VI}_{\mathrm{CTRL}}\right) / \mathrm{VI}_{\mathrm{CTRL}}\right] 100$}

Similarly, $\mathrm{VI}_{\mathrm{INF}}$ and $\mathrm{VI}_{\mathrm{CTRL}}$ were vegetation index of infested plants and control plants. Sensitivity analyses were performed for the data obtained from field studies.

\begin{tabular}{|l|l|l|l|}
\hline & RVI & NDVI & GRVI \\
\hline$r$ & -0.898 & -0.895 & -0.615 \\
\hline$R^{2}$ & $0.806^{*}$ & $0.802^{*}$ & $0.379^{*}$ \\
\hline Slope(b) & -9.8 & -604.5 & -92.3 \\
\hline Intercept(a) & 113.3 & 510.0 & 26.9 \\
\hline
\end{tabular}

Table 1: Vegetative indices and their relationship with percent leaf damage in randomly selected plants (at 70 Days after sowing) in Winter irrigated cotton variety, Surabi, 2012.

RVI - Ratio vegetative Index; NDVI - Normalised difference vegetative index; GRVI- Green Red vegetative index; $r$ is coefficient Pearson correlation coefficient and $\mathrm{R}^{2}$ is the coefficient of determination; ${ }^{\star}$ Calculated from mean of three plants (each in damaged and undamaged); DAS - days after sowing.

\section{Estimation of thrips damage based using vegetation indices}

For studying correlation and regression analysis, ten plants with varying levels of pest damage were selected from damaged plot and percent infestation was determined. The vegetative indices were calculated by taking reflectance values of the selected plants using spectroradiometer on all the days of observation and estimated only on the day when damage was observed more. The correlation between pest damage and vegetative indices is obtained by calculating Pearson correlation coefficient $(r)$ between vegetation indices and the percent pest damage, the coefficient of determination $\left(\mathrm{R}^{2}\right)$ were determined. The test of significance of the correlation coefficient was done as suggested by Rangaswamy [22]. Linear Regression equations were plotted to estimate the relation between vegetation indices and percent damage, in which when one value is known, other is calculated simultaneously.

\section{Results and Discussion}

\section{Spectral reflectance in thrips damaged plants}

The difference in reflectance curve (among different regions in a plant) obtained is due to absorption of visible light by chlorophylls present in epidermal cells of leaves and multiple reflection of NIR radiation in spongy tissues. The percent reflectance varied in different 
Page 3 of 5

regions in both damaged and healthy plants. Within visible region, the increase in red reflectance in pest damaged plants may be due to the loss of photosynthetic pigment concentration in particular chlorophylls scratching/sucking of pests. The decrease in reflectance in NIR region may be due to loss of leaf area, foliage density and other changes in canopy characteristics [23]. When graph was plotted with percent reflectance against wavelength, there was a decrease in blue $(450-520 \mathrm{~nm})$ and red $(620-680 \mathrm{~nm})$ regions while an increase in green $(520-590 \mathrm{~nm})$ and NIR region $(770-860 \mathrm{~nm})$ in damaged plants compared to undamaged plants. This finding is in accordance with the findings of Carter [11]; Shibayama et al. [24]; Riedell and Blackmer [25] and who reported that the stressed plants have a lower reflectance in NIR region (700-1300 nm), a higher reflectance in the far-red region of the spectrum, and a consequent shift of the red edge.

\section{Sensitivity of spectral bands to thrips damage}

The percent sensitivity of blue, green, red and NIR bands were 9.5, $-0.2,20.7$, and 2.9 percent respectively at 70 days after sowing, Based on magnitude, red band was found to be more sensitive to damage by thrips followed by blue band (Table 2). At 80 and 90 days after sowing, similar sensitivity values were observed which directly reflected the level of thrips infestation in the field. The NIR sensitivity values were more negative as the age of crop increased indicating severe tissue damage [26].

\begin{tabular}{|l|l|l|l|}
\hline \multicolumn{4}{|l|}{ Percent Sensitivity to thrips damage $^{*}$} \\
\hline Reflectance bands/indices & 45 DAS & 55 DAS & 65 DAS \\
\hline Blue $(450-520 \mathrm{~nm})$ & 9.5 & 3.5 & 14.6 \\
\hline Green $(520-590 \mathrm{~nm})$ & -0.2 & -1.6 & -6.9 \\
\hline Red $(620-680 \mathrm{~nm})$ & 20.7 & 13.9 & 7.1 \\
\hline NIR $(770-860 \mathrm{~nm})$ & 2.9 & -5.6 & -2.8 \\
\hline RVI & -15.5 & -15.8 & -9.3 \\
\hline NDVI & -3.3 & -2.9 & -1.8 \\
\hline GRVI & -45.2 & -24.4 & -28.4 \\
\hline
\end{tabular}

Table 2: Sensitivity of different reflectance bands to thrips damage (Winter irrigated, Surabi variety, 2012)

${ }^{*}$ Calculated from mean of three plants (each in damaged and undamaged); DAS - days after sowing.

\section{Sensitivity of spectral indices to thrips damage}

The sensitivity of RVI, NDVI and GRVI were $-15.5,-3.3$ and -45.2 respectively at 70 days after sowing. Higher the magnitude indicates the usefulness of the indices, irrespective of the sign. Hence, GRVI is more sensitive to thrips damage. The sensitivity values increased in magnitude on 80 days after sowing in all bands and later decreased slightly on 90 days after sowing which could be due to reduced pest load or crop tolerance (Figure 1). The NIR sensitivity values were more negative as the age of crop increased indicating severe tissue damage.

\section{Sensitivity curve}

The sensitivity curve was very characteristic to the damage caused by thrips on all days of observation. When a graph was plotted with sensitivity against wavelength, there was an increase in blue, decrease in green, again increase in red and finally decreases in NIR region on all days of observation (Figure 2). The percent sensitivity of spectral bands / indices can provide information on usefulness of the band for detecting pest damage. The higher the magnitude of the percent sensitivity, the higher will be the effect explained by the band / index (irrespective of the sign either positive or negative). The sign indicates if the reflectance in the given band increases or decreases with increase in damage by pest.

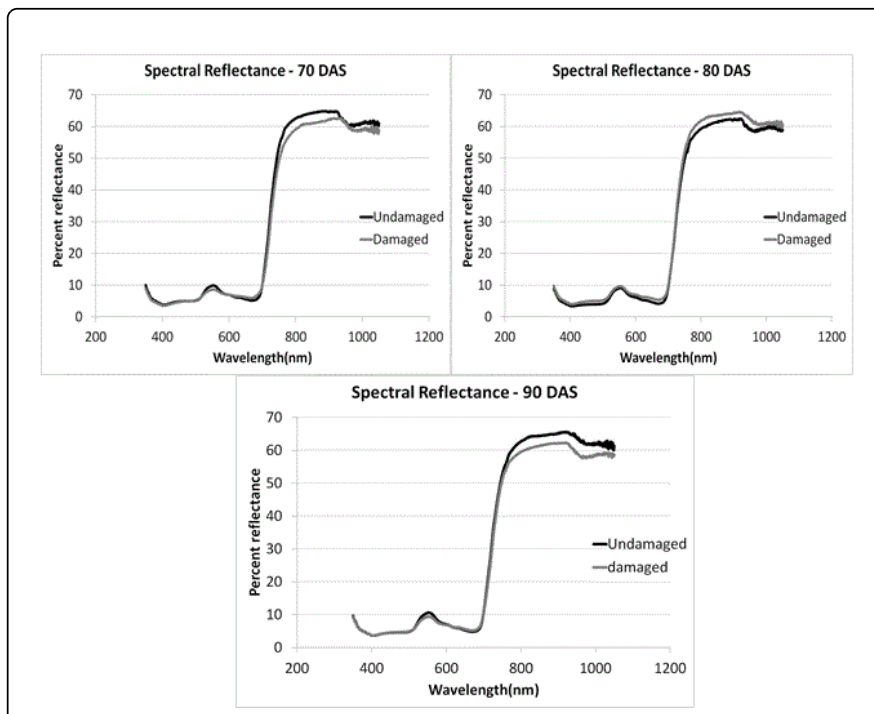

Figure 1: Spectral reflectance curves of thrips damaged and undamaged plants in Winter irrigated cotton variety, Surabi, 2012.

\section{Correlation intensity curve}

The correlation coefficients between pest damage and reflectance values were plotted against the respective wavelengths to construct linear correlation intensity curves. It was found -that the wavelengths $691,508,551$ and $710 \mathrm{~nm}$. Hence, these wavelength ranges can be used for detecting the damage caused by thrips in cotton. Prabhakar et al. [15] observed similar correlation intensity curve in leafhopper affected cotton plants and reported $376,496,691,761,1124$ and $1457 \mathrm{~nm}$ to be sensitive bands.

\section{Estimation of thrips damage based using vegetation indices}

The correlation and regression analysis, when applied between pest damage and vegetative indices, establishes the relationship between them. There was a negative correlation between pest damage and vegetative indices having significant $R^{2}$ values of vegetative indices with thrips damage indicating the capability of all these indices to estimate thrips damage (Figure 3). Regression equations were developed between percent damage and vegetative indices, thus making estimating thrips one from the other.

Per cent leaf damage by thrips $=510.0-604.5$ x NDVI; Per cent leaf damage by thrips $=113.3-9.8 \times$ RVI; Per cent leaf damage by thrips $=$ $26.9-92.3 \times$ GRVI 
These equations help in providing relative information about pest damage by substituting the predicted values of vegetative indices in the equation. It also provides the index values without remote sensing measurements by determining percent leaf damage collected from a field.

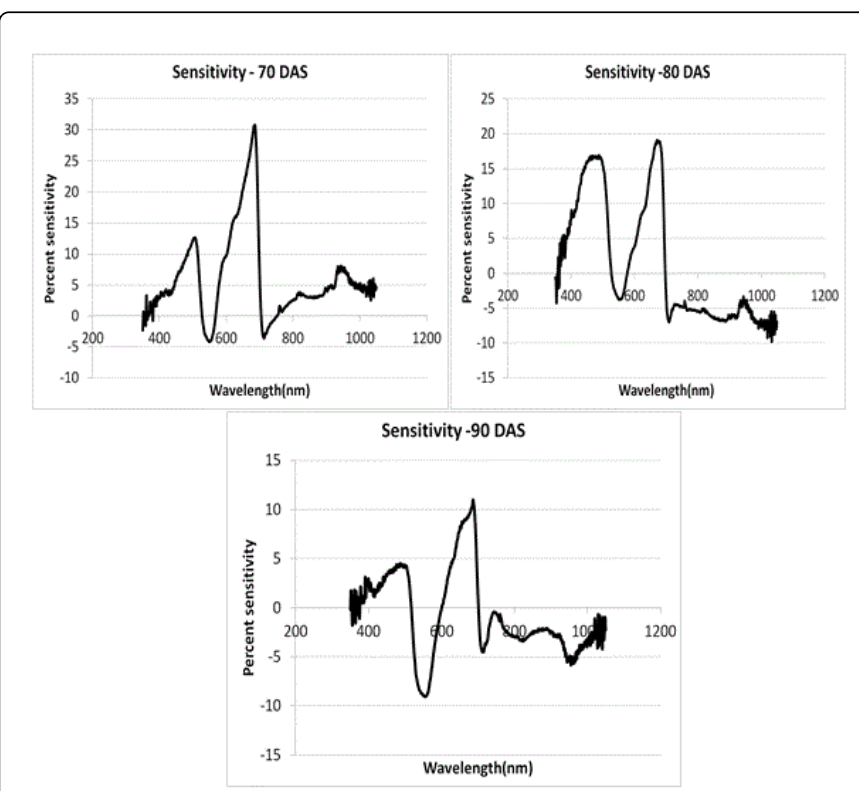

Figure 2: Sensitivity curves of thrips damaged and undamaged plants in Winter irrigated cotton variety, Surabi, 2012.

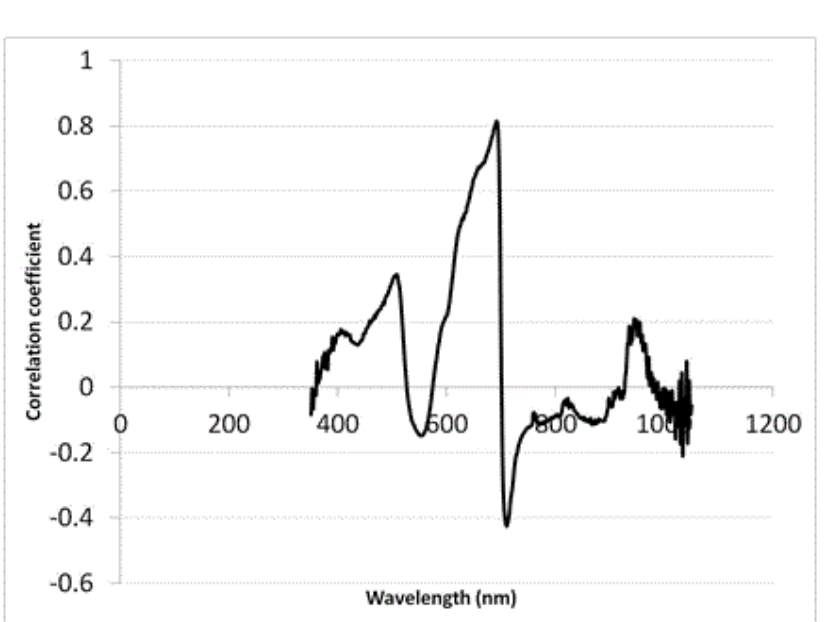

Figure 3: Correlation of reflectance to per cent leaf damage in different wavelengths due to thrips damage in cotton plants (at 50 days after sowing)

\section{Conclusion}

Hyper spectral analyses have provided more information from remotely sensed imagery than before. Comparison of mean reflectance spectra between healthy and infested plants showed significant decrease in visible regions $(400-700 \mathrm{~nm})$, while increased in the NIR region (770 to $860 \mathrm{~nm}$ ). Broadly, Red band and Green Red vegetative index (GRVI) were found to be more sensitive to thrips damage. The sensitivity curve shows single peak in blue region (at about $496 \mathrm{~nm}$ ) which is characteristic of the thrips damage. Further analysis of hyper spectral data revealed narrow bands at 508, 551, 691 and $710 \mathrm{~nm}$ found to be sensitive to thrips damage. There was a significant negative correlation between damage and vegetative indices (VIs) with significant $\mathrm{R}^{2}$ values of VIs indicating their capability to estimate damage. Linear regression equations were developed based on spectral indices and pest damage and a relationship between pest damage and VI s was established. This must be studied over a large area before it can be adapted into practice. In this study, we have taken pest damage and pest population into account, but have not controlled the other stress related factors that have similar effects on canopy reflectance. The next steps must be tested with other stress related factors under laboratories and field conditions.

\section{References}

1. Fitzgerald GJ, Maas SJ, Detar WR (2004) Spider Mite Detection and Canopy Component Mapping in cotton using hyperspectral Imagery and Spectral Mixture Analysis. Precision Agriculture 5: 275-289.

2. Summy KR, Everitt JH, Escobar DE, Alaniz MA, Davis MR (1997) Use of airborne digital video imagery to monitor damage caused by two honeydew-excreting insects on cotton. Proceedings of the 16th Biennial Workshop on Color Photography and Videography in Resource Assessment.

3. Fitzgerald GJ, Maas SJ, Detar WR (1999a) Early detection of spider mites in cotton using multispectral remote sensing. Proceedings of the Beltwide Cotton Conferences.

4. Fitzgerald GJ, Maas SJ, Detar WR (1999b) Detection of spider mites in cotton using multispectral remote sensing. Proceedings of the 17th Biennial Workshop on Color Photography and Videography in Resource Assessment.

5. Yoder BJ, Pettigrew-Crosby RE (1995) Predicting nitrogen and chlorophyll content and concentration from reflectance spectra (400$2500 \mathrm{~nm}$ ) at leaf and canopy scales. Remote Sensing Environment 53: 199-211.

6. Blackburn GA (1998) Quantifying chlorophylls and carotenoids at leaf and canopy scales: An evaluation of some hyper spectral approaches. Remote Sensing of Environment 66: 273-285.

7. Kumar L, Schmidt KS, Dury S, Skidmore AK (2001) Imaging Spectrometry and Vegetation Science, in Imaging Spectrometry: Basic Principles and Prospective Applications/ F.D. van der Meer and S.M. de Jong, (Eds.), Dordrecht etc.: Kluwer Academic Publishers.

8. Apan A, Datt B, Kelly R (2005) Detection of Pests and Diseases in Vegetable Crops Using Hyperspectral Sensing: A Comparison of Reflectance Data for Different Sets of Symptoms. Proceedings of SSC 2005 Spatial Intelligence, Innovation and Praxis: The national biennial Conference of the Spatial Sciences Institute.

9. Luther JE, Carroll AL (1999) Development of an index of balsam fir vigor by foliar spectral reflectance. Remote Sensing and Environment 69: 241-252

10. Abdel-Rahman EM, Ahmed FB, Van den Berg M, Way MJ (2010) Potential of spectroscopic data sets for sugarcane thrips (Fulmekiola serrata Kobus) damage detection. International Journal of Remote Sensing 31: 4199-4216.

11. Carter GA (1993) Responses of leaf spectral reflectance to plant stress. American Journal of Botany 80: 239-243.

12. Malthus TJ, Madeira AC (1993) High-resolution spectroradiometry: spectral reflectance of field beans leaves infected by Botrytis fabae. Remote Sensing Environment 45: 107-116.

13. Yang, CM, Chen CH, Chen RK (2007) Changes in spectral characteristics of rice canopy infested with brown planthopper and leaf folder. Crop Science 47: 329-335. 
Citation: Ranjitha G, Srinivasan MR, Rajesh A (2014) Detection and Estimation of Damage Caused By Thrips Thrips tabaci (Lind) of Cotton Using Hyperspectral Radiometer. Agrotechnol 3: 123. doi:10.4172/2168-9881.1000123

Page 5 of 5

14. Jones JD, Jones JB, Lee WS (2010) Diagnosis of bacterial spot in tomato using spectral signatures. Computers and Electronics in Agriculture 74: 329-335.

15. Prabhakar M, et al. (2011) Use of ground based hyper spectral remote sensing for detection of stress in cotton caused by leafhopper. Computers and Electronics in Agriculture 79:189-198.

16. Luedeling E, Hale A, Zhang M, Bentley WJ, Dharmasri LC (2009) Remote sensing of spider mite damage in california peach orchards. International Journal of Applied Earth Observation and Geoinformation 11: 244-255.

17. Richardson AJ, Wiegand CL (1977) Distinguishing vegetation from soil background information. Photogrammatic Engineering and Remote Sensing 43:1541-1552.

18. Tucker CJ (1979) Red and Photographic Infrared Linear Combinations for Monitoring Vegetation. Remote Sensing Environment 8: 127-150.

19. Mirik M, Michels JR, Kassymzhanova GJ, Mirik S, Elliott NC, et al. (2006) Using digital image analysis and spectral reflectance data to quantify greenbug (Homoptera: Aphididae) damage in winter wheat. Computers and Electronics in Agriculture 51: 86-98.

20. Yang Z, Rao MN, Elliott NC, Kindler SD, Popham TW (2009) Differentiating stress induced by greenbugs and Russian wheat aphids in wheat using remote sensing. Computers and Electronics in Agriculture 67: 64-70.

21. Motohka T, Nasahara KN, Oguma H, Tsuchida S (2010) Applicability of Green-Red Vegetation Index for Remote Sensing of Vegetation Phenology. Remote Sensing 2: 2369-2387

22. Rangaswamy R (1995) Correlation and regression analysis. A Textbook of Agricultural Statistics. New age international publishers limited Wiley eastern limited, New Delhi.

23. Gausman HW (1974) Leaf reflectance of near infrared. Photogrammatic Engineering and Remote Sensing 40: 57-62.

24. Shibayama M, Takahashi W, Morinaga S, Akiyama T (1993) Canopy water deficit detection in paddy rice using a high resolution field spectroradiometer. Remote Sensing Environment 45: 117-126.

25. Riedell WE, Blackmer TM (1999) Leaf reflectance spectra of cereal aphiddamaged wheat. Crop Science 39: 1835-1840.

26. Wiegand CJ, Richardson AJ, Escobar DE, Gerber mann AH (1991) Vegetation indices in crop assessments. Remote Sensing Environment 35:105-119. 